\title{
ОЦЕНКА УРОВНЯ И КАЧЕСТВА СТОМАТОЛОГИЧЕСКИХ УСЛУГ
}

\begin{abstract}
ASSESSMENT OF THE LEVEL AND QUALITY OF DENTAL SERVICES

\section{B. Hubieva}

V. Zelenskiy

Summary. According to WHO (2012), Russian and foreign researchers data, prevalence rate of dental diseases among children reaches $75-95 \%$, among adults — 100\%, and in age groups above 35 years old, dental and mouth cavity problems become the primary concern [6].

Despite intensification of the sanitation process in clinical dentistry, many researchers note the tendency of decrease in national dental health. Dealing with such an important medical-social goal as radical decrease of dental illnesses is in the area of complex approach not only to realization of sanitation-prophylaxis measures, but also in using novel ideas in dental services organization [1].
\end{abstract}

The problems of legal regulations and administrative management of dental clinics in new economic conditions are key priority areas for the modern Russian medical industry [4].

Rapid development of medical services market, improvement medical insurance services, providing more freedom for medical organizations in implementation of its activities marked the significance of search for more effective mechanisms of dental clinics work organization, focused on dental services improvement $[2,3]$.

High quality medical care should provide financial-economy and medicalsocial efficacy of healthcare development programs, determined to improve population quality and duration of life. Herewith, currently there are no unified criteria to determine medical care quality in Russia and abroad. [5].

The expediency to perform independent medical expertise of performed dental services is beyond dispute. Objectification of final treatment result evaluation is possible only when the patient medical condition data is available, determination of causal relationships between medical personnel actions and their consequences for the health of a citizen.

Keywords: quality control, dental services, medical expertise, dental diseases.

\author{
Хубиева Бэлла Хасановна \\ Ассистент, Северо-Кавказская Гуманитарная \\ Академия \\ Bella8800@mail.ru \\ Зеленский Владимир Александрович \\ Д.м.н., профессор, Ставропольский Государственный \\ Медицинский Университет \\ Moon175@yandex.ru
}

Аннотация. По данным В03 (2012), отечественных и зарубежных исследователей, распространенность стоматологических заболеваний среди детского населения достигает 75-95\%, взрослого - 100\%, причём в возрастных группах населения старше 35 лет проблемы, связанные с болезнями зубов и полости рта, выходят на первое место [6].

Несмотря на интенсификацию современного санационного процесса в клинической стоматологии, многие исследователи отмечают тенденцию ухудшения стоматологического здоровья нации. Решение такой важной медико-социальной задачи как радикальное снижение стоматологической заболеваемости лежит в плоскости комплексного подхода не только к реализации санационно- профилактического направления, но и в использовании новаторских идей в организации стоматологической службы [1].

Проблемы правового регулирования и административного управления стоматологическими учреждениями в новых экономических условиях являются приоритетными направлениями современной отечественной медицины [4].

Бурное развитие рынка медицинских услуг, совершенствование системы медицинского страхования, предоставление медицинским организациям большей самостоятельности в осуществлении своей деятельности актуализировали значимость поиска более эффективных механизмов организации деятельности стоматологических поликлиник, направленных на повышение качества стоматологической помощи [2,3].

Качественная медицинская помощь должна обеспечивать финансово-экономическую и медико-социальную эффективность программы развития здравоохранения, направленной на повышение продолжительности и качества жизни населения. При этом в России и за рубежом до настоящего времени нет унифицированных критериев определения качества медицинских услуг [5].

Целесообразность проведения независимой медицинской экспертизы оказанных стоматологических услуг не вызывает сомнений. 0бъективизация оценки конечного результата лечения возможна только при наличии данных о состоянии здоровья пациента, установления причинно-следственной связи между действиями медицинского персонала и их последствиями для здоровья гражданина.

Ключевые слова: контроль качества, стоматологические услуги, медицинская экспертиза, стоматологические заболевания. 


\section{Ввемение}

H а современном этапе развития стоматологической службы пристальное внимание уделяется вопросам качества медицинских услуг. Резерв повышения эффективности оказания медицинской помощи лежит в плоскости оптимизации контроля качества. Пока в отечественной медицине нет стандартизированных подходов к определению уровня и качества медицинских услуг. Основная цель предоставления качественной медицинской помощи, в первую очередь - это увеличение продолжительности жизни пациента, во-вторых, обеспечение программ современного развития медицины, а именно их медико-социальной, экономической и технологической действенности и отдачи.

В Гражданском кодексе РФ, несмотря на обширное использование в бытовом обиходе понятия «качество медицинской услуги», официальное его определение не сформулировано. Определяя правовые гарантии потребителю, законодатель не создает заведомо нерентабельных условий экономического положения стоматологической поликлинике, что способствует свободному выбору методик достижения соответствующего качества. Стандарт стоматологической помощи это - совокупность медицинских технологий, методов лечения, объёма медицинских услуг, квалификации медицинского персонала и т.д. Для апробации, негосударственной стоматологической МО ООО «РЕНЕССАНС» диссертантом предложена новая схема взаимодействия врачей и медицинской подсистемы. Им сформулирована трактовка термина «стандарт стоматологической помощи»наивысшая степень профессиональных коммуникаций медицинской системы, направленная на повышение уровня стоматологического здоровья через внедрение протоколов ведения стоматологического больного, стандартов стоматологических услуг, порядков оказания стоматологической помощи.

\section{Задачи стандарта:}

- сформулировать единые требования к профилактике, диагностике и лечению стоматологических заболеваний;

- оптимизировать временные затраты медицинской услуги, количество обращений и посещений пациентом врача-стоматолога;

- модернизировать систему диспансеризации стоматологических больных в соответствии с современными требованиями к санации рта.

Стоматологический лечебно-диагностический комплекс включает: обследование пациента с определением стоматологического статуса, диагностика дентальной патологии, составление индивидуализированного плана лечения, реабилитации и профилактики. В первое посещение врач-стоматолог осматривает челюстно-лицевую область, органы и ткани рта, определяет лечебную тактику и вырабатывает стратегию восстановления эстетики лица. Для мотивации участия пациента в комплексной санации использовалась мультимедийная программа «Понятная стоматология», порядок мероприятий первичного визита включает:

- комплексное обследование зубочелюстной системы;

- определение стоматологического статуса пациента;

- заполнение медицинской карты стоматологического больного и установление диагноза;

- проведение дополнительных методов исследования;

- планирование санации с оптимизацией сроков её выполнения;

- проведение профессиональной гигиенической чистки зубов «32 ОК»;

- соблюдение последовательности лечебных мероприятий;

- консультации иных специалистов.

Последовательное выполнение пациентом мероприятий комплексной стоматологической санации свидетельствует о профессиональном проведении подготовительного этапа, высокой квалификации врача и отлаженном механизме взаимодействия различных специалистов и медицинской подсистемы. Нами разработан и внедрен алгоритм порядка движения пациента между клиническими подразделениями стоматологической МО «Дорожная карта» пациента в стоматологической МО определяется в соответствии с клинико-рентгенологическим диагнозом по МКБ-10, дополнительного обследования или консультации специалиста с обоснованием фиксируется в медицинской карте стоматологического больного. На первом этапе санации выполняются следующие условия:

- зубы и корни зубов, потерявшие функциональную ценность, удаляются;

- каналы депульпированных зубов пломбируются до верхушки;

- при патологии пародонта и слизистой оболочки полости рта проводится специализированное лечение у пародонтолога;

- при наличии изменений в периапикальных тканях врачебный консилиум определяет способность дальнейшего функционирования зуба;

- решение консилиума отражается в медицинской карте стоматологического больного.

Итоговый результат комплексной санации фиксируют как законченный клинический случай (с выполнением ОПТГ), о чем в медицинскую карту вносится соот- 
ветствующая запись за подписью врача. Законченным случаем лечения является любая завершенная медицинская услуга (лечение зуба, санация рта, постановка ортопедических и ортодонтических конструкций и т.д.). После выполнения лечебных мероприятий врач-стоматолог сообщает регистратору о завершении санации, пациенту оформляется гарантийный талон, и он уведомляется о дате следующего визита к врачу-стоматологу.

Нарушением стандарта коммуникаций медицинской системы и взаимодействия врачей и медицинской подсистемы считается:

- невыполнение врачом-стоматологом алгоритма первичного обращения пациента (до введения контроля качества отмечено у 54\%, после- у $7 \%$ больных);

- лечение больного без предварительной профессиональной гигиены (до введения контроля качества имелось в 49\%, после- в 4\% случаев);

- неправильный выбор метода лечения (до совершенствования системы контроля качества встречалось в 31\%, после - в 3\% случаев);

- отсутствие согласованного с другими специалистами подхода к лечению (до нововведения наблюдалось в 39\%, после - в 6\% случаев);

- несогласованность индивидуальных планов лечения (до введения контроля качества лечения отмечено в $28 \%$, после - в $6 \%$ случаев).

К исключительным случаям нарушения взаимодействия пациента и медицинской системы относятся:

- нежелание пациента продолжать лечение в данной МO;

- ухудшение состояния общесоматического здоровья пациента;

- обращение по поводу острой зубной боли;

- кратковременность пребывания пациента в городе Черкесске.

Каждый подобный клинический случай анализируется администрацией МО.

Полноценное удовлетворение потребностей пациента в стоматологической помощи является целью осуществления контроля качества стоматологических услуг. В стоматологических МО разных форм собственности экспертиза законченных случаев лечения проводится руководителем структурного подразделения или врачом-экспертом:

- в день завершения санации рта или лечения отдельного зуба;

- при плановом или внеплановом контроле администрации МO;

- по претензионному обращению пациентов.
Такой подход к контролю позволяет объективно оценить качество стоматологических услуг. Экспертиза законченного случая лечения проводится по требованиям системы контроля качества не реже трёх в месяц у каждого врача. У молодых специалистов и врачей, работающих с испытательным сроком, контроль качества лечения проводится в 100\% законченных случаев.

Планирование экспертизы отдалённых результатов лечения проводится, по необходимости отложенного контроля (12, 24 месяца с момента оказания услуги), но не менее трёх законченных случаев у каждого врача в месяц. Экспертиза итоговых результатов стоматологической услуги проводится в соответствии с «протоколом по законченному случаю лечения» Возникающие у пациента претензии к качеству стоматологических услуг проверяются в процессе внеплановых контрольных осмотров. Такой визит пациента считается регистратором «внеплановым контрольным осмотром», и соответствующая запись заносится в реестр.

Согласно оценочным критериям, заполняются все графы протокола, для вычисления среднего балла суммируют число оценок по каждому параметру и умножают на то число баллов, которое соответствует данному параметру: 5 баллов - полностью соответствует; 3 балла - вполне соответствует; 0 баллов - совершенно не соответствует. Факт экспертизы регистрируется в «Журнале проведения экспертизы законченных случаев», протокол экспертизы заверяется главным врачом.

В журнале экспертизы фиксируются паспортные данные пациента, ФИО лечащего врача, вид экспертизы, балльная оценка и конечный результат. Далее, один раз в неделю медицинский статист формирует отчет о проведённой экспертизе по каждому врачу, отделению и МО в целом. После осмотра заполняется «протокол внепланового контрольного осмотра». В протоколе отражают жалобы, данные объективного осмотра и рентгенологического обследования, претензия пациента или причина внепланового контрольного осмотра. Протокол вносят в «Журнал внеплановых контрольных осмотров» указывают паспортные данные пациента, Ф.И.О. лечащего врача, основание внепланового контроля, заключение (гарантийный или не гарантийный случай, дополнительная экспертиза). Один раз в неделю «протоколы внеплановых контрольных осмотров» предоставляются регистратору по информации для формирования отчёта о внеплановых контрольных осмотрах: по каждому врачу, отделению и в целом по МО. Контроль качества оказанных услуг в ортопедическом отделении проводит заведующий, им оценивается не менее трети ортопедических работ, сдаваемых 
врачами в течение месяца. Обязательный контроль качества проводится после выполнения определённых видов ортопедической работы:

- керамические зубные протезы и реставрация;

- зубные протезы с опорой на имплантаты;

- зубные протезы из сплавов драгоценных и благородных металлов;

- комбинированные бюгельные и металлокерамические протезы;

- несъёмные конструкции с металлокерамическими зубами более 6 ед.

Заведующий ортопедическим отделением также ведет:

- учёт оценочных листов по сданным протезам;

- входной и выходной контроль качества ортопедической работы;

- вычисляет суммарную результативность по оценочным листам;

- определяет средние значения оценок по входящему контролю качества.

После определения средних значений по входному и выходному контролю заведующий вносит эти оценки в реестр ортопедической работы. По ежемесячному отчёту анализируют результаты средних баллов по отделению, лаборатории, врачам, техникам и по виду выполненной ортопедической работы. Ежемесячно заведующий суммирует значения оценок качества и вычисляет:

- средний балл удовлетворённости врачей-стоматологов-ортопедов качеством зуботехнической работы, отдельно по видам работы и в целом по лаборатории;

- средний балл удовлетворённости зубных техников качеством оттиска и препарирования по врачам и в целом по MO;

- процент экспертизы выходного контроля качества, проведённой им лично;

- количество брака по вине лечащего врача и зубного техника.

Первые три показателя являются ключевыми для оценки эффективности работы заведующего ортопедическим отделением.

Поэтапный контроль качества в зуботехнической лаборатории призван предупредить возможность брака при изготовлении зубных протезов. Оценка качества зуботехнической работы возложена на старшего зубного техника-эксперта. Данные о качестве изготовленных протезов вносятся в «оценочные листы» и используются:

- при рассмотрении гарантийных случаев в стоматологическом ортопедическом лечении;

- при анализе клинико-экспертной комиссией данных входного и выходного контроля качества ортопедической конструкции;
- при вынесении коллегиального решения о повышения уровня категории специалиста на плановой аттестации;

- при планировании обучения врачей и зубных техников, разборах случаев брака ортопедической конструкции на медицинском совете поликлиники.

Достоверно установлено, что низкое качество выполнения этапа зуботехнической работы не позволяет достичь необходимого качества ортопедических конструкций. Разработка Положения и Инструкции о контроле качества в зуботехнической лаборатории является важным моментом системы контроля качества стоматологической ортопедической помощи. Между врачами-стоматологами-ортопедами и зубными техниками в системе взаимоотношений целесообразно выделить следующие виды контроля:

- входной тест-контроль качества, проводится заведующим зуботехнической лабораторией или старшим зубным техником-экспертом;

- выходной тест-контроль качества, определяет соответствие изготовленной ортопедической конструкции критериям качества;

- поэтапный контроль качества, оценивает каждый этап изготовления зубного протеза для исключения брака.

В журнале «Регистрации зуботехнической работы» фиксируют номер заказ наряда, устанавливают порядковый номер оценочного листа. На лицевой стороне оценочного листа фиксируются данные входного контроля, показатели выходного контроля - на оборотной стороне оценочного листа. На первом зуботехническом этапе по входному контролю качества оценивают оттиск и отлитую модель, заполняется «Оценочный лист входного контроля качества».

При наличии брака в графе «Совсем не соответствует» выставляется неудовлетворительная оценка. После исправления выявленного дефекта зуботехническая работа оценивается повторно. Переделку ортопедической конструкции на любом этапе изготовления фиксируют в «Журнале учёта доработок» с указанием причин брака. Для предупреждения формального отношения к заполнению оценочных листов на входном контроле в зуботехнической лаборатории проводится выборочный контроль качества заполнения оценочных листов. Особое внимание заведующий ортопедическим отделением уделяет оценочным листам с отметкой «не соответствует», с тщательным повторным контролем работ, отправленных на доработку.

Оптимизация клинико-экспертного контроля во многом зависит от эффективности подходов 
к оценке в баллах качества эндодонтического лечения. Контроль качества обеспечивают заведующий терапевтическим отделением, врач-эксперт и КЭК. Балльная шкала оценки качества эндодонтического лечения имеет свои критерии и контрольные значения, соответствующие протоколу эндодонтического лечения. Каждый критерий имеет 1 или 0,5 балла; если лечение зуба не отвечает требованиям, в протоколе присваивается 0 баллов. При оценке контрольных параметров, находящихся в поле допустимых значений, возможны определённые колебания от установленного показателя, тогда зубу добавляется 0,5 балла. Контрольные показатели эндодонтического лечения имеют следующую градацию баллов: «0» - несоответствие требованиям протокола, «0,5» - допустимый; «1»- соответствующий требованиям протокола Отдельно фиксируются данные о неудовлетворительном лечении с оценкой «0» баллов, требующие повторного лечения: ошибки пломбирования, слом эндодонтического инструмента; перфорация корня; несоблюдение диагностического стандарта; отсутствие информированного добровольного согласия. В процессе оценки качества эндодонтического лечения контролируются соответствие поставленного диагноза МКБ - 10, наличие RVG-диагностики, оформление медицинской документации и лечение в соответствии с Протоколом эндодонтического лечения. Соответствие эндодонтического лечения стандарту оценивается 1 баллом, при несоответствии присваивается оценка «0». За наличие в МКСБ информированного добровольного согласия на эндодонтическое лечение присваивается 1 балл, при отсутствии - 0. Использование коффердама оценивается 0,5 балла, при отсутствии - 0. Создание эндодонтического доступа имеет 0,5 балла, при отсутствии оптимального доступа - 0. Наличие RVG с файлами в МКСБ оценивается 1 баллом, отсутствие - 0 . За аппаратурную обработку корневых каналов в соответствии со стандартами присваивается 0,5 балла. Медикаментозная обработка корневых каналов зубов в соответствии со стандартами оценивается в 1 балл, отсутствие - 0. Пломбирование канала корня зуба до физиологической верхушки обозначается 1 баллом, при выведении за апекс корня пломбировочного материала в небольшом количестве (до 1,5 мм) - 0,5 балла. Неполное пломбирование корневого канала более 2 мм до апекса или выведение пломбировочного материала за верхушку корня оценивается 0 баллов. Полное обтурационное пломбирование канала - 1 балл, зазор между корневой и коронковой пломбой в 0,5 мм оценивается как 0,5 балла, дефект между корневой и коронковой пломбой более 0,5 мм - 0 баллов. Герметичное пломбирование корневого канала по всей длине имеет 1 балл, при обнаружении пор в пломбе корня зуба или щели по краю всего зуба - 0 баллов. Лечащему врачу за нулевую оценку выносится предупреждение с отметкой в индивидуальном листке контроля.

Контроль качества эндодонтического лечения врач-эксперт осуществляет ежедневно по медицинским картам, в процессе его проведения выявляются следующие врачебные ошибки:

- перфорация корня зуба;

- слом инструмента внутри канала зуба;

- пломбирование корневого канала не до верхушки;

- выведение пломбировочного материла за апекс более 1,5 мм;

- эндодонтическое лечение не отвечает назначенному диагнозу.

После экспертизы МКСБ на специалиста заполняется «Индивидуальный лист контроля». Эксперт ежемесячно по каждому врачу отдельно готовит отчёт по форме «Анализ эндодонтического лечения», где указывается общее число полученных баллов по эндодонтии, общее число пролеченных корневых каналов и зубов, число осложнений и обнаруженных ошибок, процент выполнения параметров эндодонтического лечения. При выявлении врачебных ошибок данные пациента заносят в реестр «Пациенты под наблюдением», содержащий информацию о допущенных случаях брака и мероприятиях направленных на предупреждение осложнений. Дополнительное лечение по исправлению врачебных ошибок считается гарантийным и осуществляется на безвозмездной основе. Эксперт после устранения врачебных ошибок повторно оценивает дополнительное лечение и заполняет «Лист контроля эндодонтического лечения».

Соблюдение преемственности в оказании всех видов стоматологической помощи и реставрации зубов, повышает эффективность лечебно-профилактических мероприятий Первичным звеном междисциплинарного взаимодействия является гигиенист стоматологический. Всем посетителям стоматологических МО проводится комплекс профессиональной гигиены, за исключением обращений с острой зубной болью. Вторым звеном междисциплинарного взаимодействия считается направление к врачу-стоматологу-терапевту. Третьим звеном при наличии показаний к удалению или эндодонтической хирургии является врач-стоматолог-хирург. Следующим звеном взаимодействия медицинской подсистемы является врач-стоматолог-ортопед.

Результаты исследования дают все основания подтвердить, что действенная эффективная система контроля за качеством предоставляемых услуг существенно повышает культуру, уровень и конечный результат стоматологической помощи профильным больным. 


\section{ЛИТЕРАТУРА}

1. Алимский А. В. Мотивация обращаемости населения за стоматологической помощью в частные структуры / А. В. Алимский, И. А. Лемберг, И. М. Рабинович // Клиническая стоматология. - 2009.— № 1.— С. 74-76.

2. Бутова В. Г. Предпринимательская деятельность стоматологических организаций / В. Г. Бутова, К. А. Пашков, Н. Н. Мальгинов. - М.,2007.—292с.

3. Бутова В. Г. Управление качеством стоматологической помощи / В. Г. Бутова, Э. В. Зимина, М. 3. Каплан. — М.: Издательский Дом «STB00K», 2007. — 224 с.

4. Данилов Е. 0. Проблемы организации стоматологической помощи в системе ОМС / Е. 0. Данилов // Институт стоматологии.— 2009.— № 3.— С. 22-23.

5. Peeters F. R. Risks for oral health with the use of antidepressants / F. R. Peeters, M.W. de Vries, A. Vissink // Gen Hosp Psychiatry. — 2008. — No 20 (3). — P. 150-154.

6. Johnson N. Practical prevention / N. Johnson // FDI World, No/Des. - 2017. - P. 10-15.

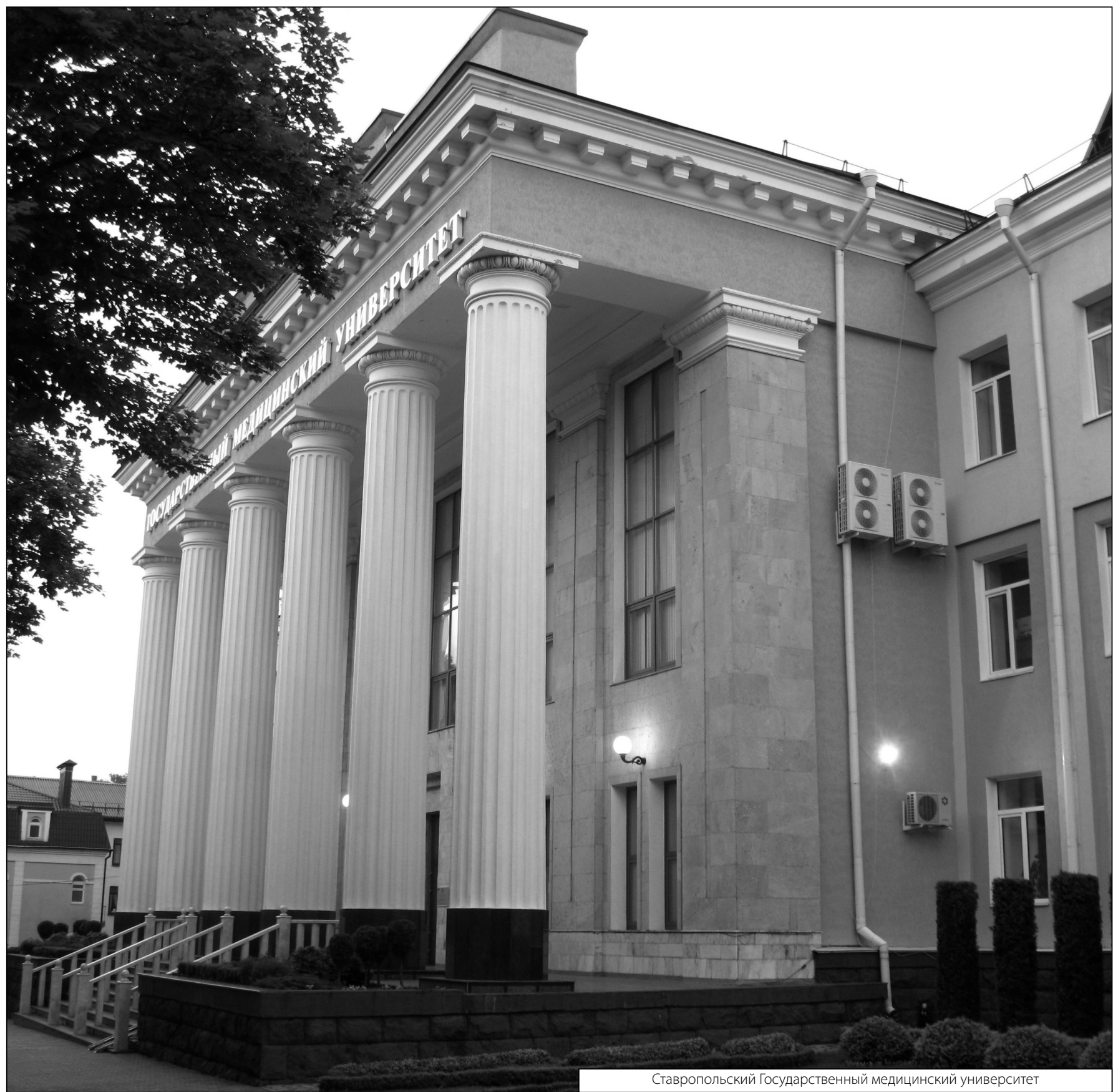

